\title{
Intraocular Pressure Control after Trabeculectomy with Adjunctive Use of Mitomycin-C versus Bevacizumab: A Hospital Based Study
}

\author{
P. S. Mahar ${ }^{1}$, Sobia Tabassum², Mujahid Inam ${ }^{3}$, Muhammad Faaz Malik ${ }^{4}$, Tauseef Mahmood ${ }^{5}$ \\ ${ }_{1-5}$ Isra Postgraduate Institute of Ophthalmology, Karachi
}

\begin{abstract}
Purpose: To compare the control of intra ocular pressure (IOP) after trabeculectomy with adjunctive use of Mitomycin-C (MMC) versus Bevacizumab.

Study Design: Quasi experimental study.

Place and Duration of Study: Al-Ibrahim Eye Hospital, Isra Postgraduate Institute of Ophthalmology, Karachi, from August 2017 to August 2019.

Methods: One hundred and six patients of either gender, fulfilling the inclusion criteria were planned for trabeculectomy with adjunctive use of Mitomycin-C (MMC) or Bevacizumab. Each group consisted of 53 patients (53 Eyes). The patients diagnosed with Primary Open Angle Glaucoma (POAG) with IOP $\square 21 \mathrm{~mm} \mathrm{Hg}$ and not controlled with topical anti-glaucoma medication were selected. Data were analyzed by using SPSS Version 22.0. Independent sample t test was used to check significance between two drugs. Paired sample t test was used to check significance of pre and post-operative IOP.

Results: Mean age of patients was $56.67 \pm 7.34$ years. Mean preoperative IOP was $31.51 \pm 9.66 \mathrm{~mm} \mathrm{Hg}$ in MMC group and $29.21 \pm 7.69 \mathrm{~mm} \mathrm{Hg}$ in Bevacizumab group. At first postoperative day, mean IOP after use of MMC was $14.75 \pm 9.46 \mathrm{~mm} \mathrm{Hg}$ and for Bevacizumab was $15.07 \pm 6.47 \mathrm{~mm} \mathrm{Hg}$ (p-value 0.001). Similarly, at one year follow-up, mean IOP for MMC group was $11.26 \pm 2.31 \mathrm{~mm} \mathrm{Hg}$ and for Bevacizumab was $11.73 \pm 2.12 \mathrm{~mm} \mathrm{Hg}$ (p-value 0.001).
\end{abstract}

Conclusion: There was significant reduction in IOP in both MMC and Bevacizumab groups. However, the difference between the two groups was not statistically significant at mean follow-up of one year.

Key Words: Primary Open Angle Glaucoma, Mitomycin-C, Intraocular Pressure, Bevacizumab, Trabeculectomy.

How to Cite this Article: Mahar PS, Tabassum S, Inam M, Malik MF, Mahmood T. Intraocular Pressure Control after Trabeculectomy with Adjunctive Use of Mitomycin-C Versus Bevacizumab: A Hospital Based Study. Pak J Ophthalmol. 2022, 38 (1): 9-15.

Doi: $10.36351 /$ pjo.v38i1.1335

Correspondence: P. S. Mahar

Department of Ophthalmology

Isra Postgraduate Institute of Ophthalmology

Karachi

Email: Salim.mahar@aku.edu

Received: September 22, 2021

Accepted: December 12, 2021

\section{INTRODUCTION}

Glaucoma is a vision-threatening condition characterized by progressive optic neuropathy and visual field loss with raised intraocular pressure (IOP) in majority of the patients. There were 60.5 million people with glaucoma worldwide in 2010 and it is was estimated that this number would be more than 79.6 million people by 2020. ${ }^{1}$ Trabeculectomy was introduced by Cairns in 1968 and is considered to be 
the gold standard to reduce IOP in patients with pharmacologically uncontrolled $\mathrm{IOP}^{2}$ Failure of trabeculectomy is associated with postoperative scarring of conjunctiva and tenon capsule at the site of filtering bleb due to inflammatory response associated with healing. ${ }^{3}$ This inflammatory response includes fibroblasts migration and proliferation leading to formation of adhesions between epi-sclera and conjunctiva, decreasing aqueous outflow with a resultant increase in IOP. ${ }^{4}$ To overcome this problem, several antimetabolites like Mitomycin-C and 5flurouracil have been used. These are antifibrotic agents that have been used successfully in trabeculectomy to delay the wound healing process. However, due to inconsistent findings in terms of IOP control, there has been need for further studies. ${ }^{5-7}$

Mitomycin C (Kowa, Japan) is an antineoplastic/ antibiotic agent isolated from soil bacterium Streptomyces Caespitosus. It inhibits the fibroblast proliferation by acting as a deoxyribonucleic acid cross-linker. It is used in medicine as a chemotherapeutic agent in treatment of a variety of cancers. Its use in glaucoma filtration surgery is a common practice because of its modulatory effects on wound healing. ${ }^{8}$ Chen et al. used MMC in patients with refractory glaucoma with successful outcome in control of IOP. Since then it is routinely used in trabeculectomy. MMC inhibits the postoperative episcleral fibrosis thus enhancing the successful outcome regarding the control of IOP. ${ }^{\text {? }}$

Vascular endothelial growth factor (VEGF) is a cytokine with multiple effects on wound healing. It stimulates the scar formation through collagen deposition, angiogenesis and epithelialization. VEGF has been shown to be elevated in glaucoma patients and is suggested that it might be playing a role in the scar formation after filtering surgery. Bevacizumab (Avastin, Roche Pakistan) is a full-length humanized monoclonal antibody that binds to all isoforms of VEGF. It has been approved by the US Food and Drug administration for intravenous treatment of metastatic colorectal cancer. It is used off label in various choroidal and retinal vascular disorders universally. There has been some evidence that it reduces filtering bleb failure after sub-conjunctival injections. ${ }^{10}$

Multiple publications in literature has suggested different results with the use of Bevacizumab in trabeculectomy. Akkan and colleagues conducted a study in Turkey and found that post-operative IOP target was achieved in $71 \%$ of eyes in MMC group while $33 \%$ success in patients in Bevacizumab group ( $p=0.02)$, at 12 months follow-up. ${ }^{11}$ Nilforushan et al. reported a study from Iran where they found statistically significant difference in IOP control between the two groups; $34 \%$ in Bevacizumab and $56 \%$ in MMC group $(p=0.32)^{12}$. Sengupta and coworkers however reported that Bevacizumab group had better success rate than MMC group ( $90 \%$ versus $60 \% ; p=0.04){ }^{13}$

As there is limited number of studies on Bevacizumab use in glaucoma filtering surgery with inconsistent findings, we conducted this prospective study to compare the frequency of controlled IOP after trabeculectomy with the adjunctive use of MMC and Bevacizumab. The primary end-point was control of IOP of $\square 18 \mathrm{~mm} \mathrm{Hg}$ without any added anti-glaucoma drug or $30 \%$ reduction in IOP from baseline at oneyear follow-up. The secondary outcomes were; associated adverse effects with each drug and any change in visual acuity. We also evaluated the bleb morphology in both drugs.

\section{METHODS}

This study was carried out in Glaucoma department of Al-Ibrahim Eye Hospital/Isra Postgraduate Institute of Ophthalmology, Karachi from August 2017 to August 2019. The study commenced after clearance from the hospital Research Ethical Committee and was carried out in accordance with declaration of Helsinki. Sample size was calculated with Open Epi sample calculator, using success of $94.4 \%$ of MMC group with $95 \%$ confidence interval and 5\% margin of error. ${ }^{12}$ The final sample size was 106 patients with 53 patients in MMC group and 53 patients in the Bevacizumab group. Patients were divided by non-probability consecutive sampling. All participants were given information about the study and an informed consent was taken. Patients $>40$ years of age and having a diagnosis of primary open angle glaucoma (POAG) with intraocular pressure (IOP) of more than 21 $\mathrm{mmHg}$, uncontrolled medically and having glaucomatous optic disc cupping were included in the study. We excluded patients with angle closure glaucoma, secondary glaucoma, corneal diseases, uveitis (or history of uveitis) and with a history of any intraocular surgery.

A detailed history was taken from all patients regarding any comorbids, ocular trauma, antiglaucoma medications with dosage and duration. 
Patients were also inquired about any addiction and family history of glaucoma.

Before surgery, all patients had detailed ocular examination including best-corrected visual acuity (BCVA), slit lamp bio-microscopic examination of anterior segment with recording of IOP using Goldman Applanation Tonometer (GAT). Gonioscopy was performed using Goldman two-mirror lens. Dilated fundus examination was carried out with +90 diopter Volk lens. Every patient had visual field examined on Humphrey Field Analyzer, Central Corneal Thickness (CCT) was determined and optical coherence tomography (OCT) was performed for Retinal Nerve Fiber Layer (RNFL) thickness and macular analysis.

Pre-operative blood pressure and blood sugar of all the patients were recorded. Intravenous Mannitol $1 \mathrm{gram} / \mathrm{Kg}$ body weight was given 1 hour before surgery whenever required. Pupil was miosed preoperatively with single drop of pilocarpine $2 \%$ to prevent lens damage and to facilitate peripheral iridectomy.

All surgeries were performed using retrobulbar 2\% xylocaine local anesthesia. Surface anesthesia was achieved with topical Proparacaine drops (Alcaine Alcon, Belgium). The operated eye was prepped and draped. Each patient underwent a fornix-based trabeculectomy. A 6/0 vicryl traction suture was inserted onto superior cornea. A fornix based flap of conjunctiva and tenon capsule was fashioned superiorly. Episcleral tissue was cleared and major vessels cauterized with wet-field bipolar cautery. Incision was made for $50 \%$ scleral thickness, to create a trapdoor lamellar scleral flap. The flap was triangular in shape of about $4 \times 4 \mathrm{~mm}$. In group one, Mitomycin$\mathrm{C}$ was applied in sponge form on sclera and under the scleral flap for 3 minutes duration and then washed with $20 \mathrm{ml}$ of balanced salt solution (BSS) for 30 seconds. Paracentesis was done on temporal side and anterior chamber was maintained with $1 \%$ Sodium Hyaluronate viscoelastic (Provisc - Alcon, Belgium). A peripheral iridectomy was performed and corneoscleral block was removed measuring about $1 \times 1 \mathrm{~mm}$. Scleral flap and conjunctiva were closed with $10 / 0$ nylon sutures.

In patients receiving Bevacizumab, same steps were taken for trabeculectomy without using MMC soaked sponges. However, at the end of procedure, $0.1 \mathrm{ml}(2.5 \mathrm{mg})$ of Bevacizumab was taken in $1 \mathrm{ml}$ syringe with 30 gauge needle. The needle was introduced sub-conjunctively away from the scleral flap site and forwarded over the flap with deposition of the drug. The point of needle entry was pressed with cotton applicator to avoid reflux of the drug.

Our postoperative treatment regimen included Moxifloxacin $0.3 \%$ drops (Vigamox - Alcon, Belgium) every hour for first 24 hours, 2 hourly for next 3 days followed by 4 times a day for 4 weeks. We used Dexamethasone 0.1\% drops (Maxidex - Alcon, Belgium) every hour for 24 hours, 2 hourly for 4 weeks, then 4 times a day for another 6 weeks. All patients were examined on day 1 , one week, 4 weeks, 3 months, 6 months and 12 months postoperatively.

Data were analyzed by using SPSS Version 22.0. Mean and standard deviation was calculated for quantitative variables like age and IOP (pre and post treatment). Frequencies with percentages were presented for qualitative variables like complications, gender and type of glaucoma. Independent sample t test was used to check significance between two drugs. Paired sample t test was used to check significance of pre and post-operative IOP.

\section{RESULTS}

A total of 106 patients (106 eyes) including 63 $(59.43 \%)$ male and $43(40.56 \%)$ female were recruited in the study. Mean age of the patients was $56.67 \pm$ 7.34 years (range $40-70$ years). Patients were divided into two groups based on drug prescribed by an ophthalmologist. Nine patients in MMC group and eleven patients in Bevacizumab group were lost to followup at the end of 1 year. Therefore, 44 patients in MMC group and 42 patients in Bevacizumab group were available for the final analysis.

Pre-operatively mean IOP in MMC group was $31.51 \pm 9.66 \mathrm{~mm} \mathrm{Hg}$. This was reduced to $11.26 \pm$ $2.31 \mathrm{~mm} \mathrm{Hg}$ at one-year postoperatively with a pvalue of 0.001 . In Bevacizumab group, preoperatively mean IOP was recorded as $29.21 \pm 7.69 \mathrm{~mm} \mathrm{Hg}$ and was dropped to $11.73 \pm 2.12 \mathrm{~mm} \mathrm{Hg}$ at one-year follow-up with a p-value 0.001 respectively (Table 1).

At day 1, $41(77.3 \%)$ out of 53 patients had controlled IOP ( $\square 18 \mathrm{~mm} \mathrm{Hg}$ ) in MMC group. While after the use of Bevacizumab, frequency of controlled IOP of $\square 18 \mathrm{~mm} \mathrm{Hg}$ was noticed in 48 (90.56\%) patients at first day post-operatively. Similarly, at one year, all $44(100 \%)$ patients who completed follow-up had IOP of $\square 18 \mathrm{~mm} \mathrm{Hg}$ after the use of MMC. 
Whereas in case of Bevacizumab, all attended 42 (100\%) patients had controlled IOP (Table 2).

Table 1: Post-operative Comparison of Mean IOP Between Mitomycin - C \& Bevacizumab Groups

\begin{tabular}{lcccc}
\hline IOP & $\begin{array}{c}\text { MMC Group } \\
\text { Mean }\end{array}$ & P-value & Bevacizumab Group \\
Mean & P-value \\
\hline $\begin{array}{l}\text { Pre op } \\
\text { IOP }\end{array}$ & $31.51 \pm 9.66$ & - & $29.21 \pm 7.69$ & - \\
$\begin{array}{l}\text { First Day } \\
\text { Sixth }\end{array}$ & $14.75 \pm 9.46$ & 0.001 & $15.07 \pm 6.47$ & 0.001 \\
Week & $14.90 \pm 7.84$ & 0.001 & $16.27 \pm 6.59$ & 0.001 \\
Third & & & & \\
Month & $13.73 \pm 7.18$ & 0.001 & $15.02 \pm 6.15$ & 0.001 \\
Sixth & & & & \\
Month & $12.06 \pm 3.95$ & 0.001 & $12.87 \pm 3.68$ & 0.001 \\
One Year & $11.26 \pm 2.31$ & 0.001 & $11.73 \pm 2.12$ & 0.001 \\
\hline
\end{tabular}

$* \mathrm{IOP}=$ Intraocular pressure $\quad * \mathrm{MMC}=$ Mitomycin $\mathrm{C}$

Comparative analysis of IOP reduction in both groups after trabeculectomy is given in Table $\mathbf{3}$ and Figure 1.

Mean postoperative BCVA ( $\log$ MAR) was $0.68+$ 0.40 and $0.63+0.41$ in MMC and Bevacizumab groups respectively at first day postoperatively with no significant difference. (p-value 0.538). Whereas at one-year follow-up, mean postoperative BCVA (log MAR) was $0.50+0.39$ and $0.38+0.27$ in MMC and Bevacizumab groups respectively with significant difference (p-value 0.01) (Table 4)

Regarding bleb morphology, 28 (52.8\%) and 35 $(66.03 \%)$ patients had elevated bleb for MMC and Bevacizumab group at day 1 postoperatively. Similarly, at one-year follow-up, 42 (79.24\%) and 39 (73.58\%) patients had elevated bleb in MMC and Bevacizumab groups respectively. At first day postoperatively, $48(90.56 \%)$ and $51(96.22 \%)$ patients had vascularized bleb for MMC and Bevacizumab, respectively. However, at one-year follow-up, only 8 (15.09\%) and $15(28.30 \%)$ patients had vascularized bleb for MMC and Bevacizumab group.

Needling was done in one case $1(1.88 \%)$ in both MMC and Bevacizumab groups at third month post operatively. Suture lysis with argon laser was carried out at 6 weeks postoperatively in $13(24.5 \%)$ and 16 (30.1\%) patients in MMC and Bevacizumab groups.

At first day post operatively, hyphema was observed in 2 (3.77\%) eyes in MMC group and none in Bevacizumab group. Hyphema was transient and disappeared in next 3 days without any added treatment. Similarly, $10(18.8 \%)$ and 4 (7.54\%) patients had flat anterior chamber for MMC and Bevacizumab group at first day postoperatively. Two patients in MMC group developed hypotomy (IOP $\square 6$ $\mathrm{mm} \mathrm{Hg}$ ) after 3 months of surgery. One patient in each group had conjunctival leak postoperatively. All these complications resolved conservatively without any added procedure.

Table 2: Comparison of Controlled IOP after Use of MMC and Bevacizumab Post-operatively.

\begin{tabular}{|c|c|c|c|c|c|c|}
\hline \multirow[b]{2}{*}{$\begin{array}{l}\text { Post-Operative } \\
\text { Follow-ups }\end{array}$} & \multicolumn{3}{|c|}{ MMC Group } & \multicolumn{3}{|c|}{ BEVACIZUMAB Group } \\
\hline & $\begin{array}{c}\text { IOP Controlled } \\
<18\end{array}$ & $\begin{array}{l}\text { IOP Uncontrolled } \\
>>21\end{array}$ & $\begin{array}{l}\text { Patients Come } \\
\text { on Followup }\end{array}$ & $\begin{array}{c}\text { IOP Controlled } \\
<18\end{array}$ & $\begin{array}{l}\text { IOP Uncontrolled } \\
>>21\end{array}$ & $\begin{array}{l}\text { Patients Come } \\
\text { on Followup }\end{array}$ \\
\hline IOP at 1 st day & $41(77.35 \%)$ & $12(22.64 \%)$ & $53(100 \%)$ & $48(90.56 \%)$ & $5(9.43 \%)$ & $53(100 \%)$ \\
\hline IOP at 6 th week & $42(80.76 \%)$ & $10(19.23 \%)$ & $52(100 \%)$ & $42(82.35 \%)$ & $9(17.64 \%)$ & $51(100 \%)$ \\
\hline IOP at 3rd month & $43(87.75 \%)$ & $6(12.24 \%)$ & $49(100 \%)$ & $45(91.83 \%)$ & $4(8.16 \%)$ & $49(100 \%)$ \\
\hline IOP at 6th month & $46(95.83 \%)$ & $2(4.16 \%)$ & $48(100 \%)$ & $47(95.91 \%)$ & $2(4.08 \%)$ & $49(100 \%)$ \\
\hline IOP at One year & $44100 \%)$ & $0(0 \%)$ & $44100 \%)$ & $42100 \%)$ & $0(0 \%)$ & $42(100 \%)$ \\
\hline
\end{tabular}

*IOP = Intraocular pressure

$* \mathrm{MMC}=$ Mitomycin C

Table 3: Pre and Postoperative Changes in Mean IOP in Mitomycin - C Versus Bevacizumab Groups.

\begin{tabular}{|l|l|l|l|}
\hline $\begin{array}{l}\text { Intraocular } \\
\text { Pressure }\end{array}$ & Mitomycin C & Bevacizumab & $\begin{array}{c}\text { P- } \\
\text { value }\end{array}$ \\
\hline First day & $14.75 \pm 9.46$ & $15.07 \pm 6.47$ & 0.839 \\
\hline Sixth week & $14.90 \pm 7.84$ & $16.27 \pm 6.59$ & 0.340 \\
\hline Third month & $13.73 \pm 7.18$ & $15.02 \pm 6.15$ & 0.076 \\
\hline Sixth month & $12.06 \pm 3.95$ & $12.87 \pm 3.68$ & 0.293 \\
\hline One year & $11.26 \pm 2.31$ & $11.73 \pm 2.12$ & 0.364 \\
\hline
\end{tabular}

*Intraocular pressure $\quad *$ MMC $=$ Mitomycin C

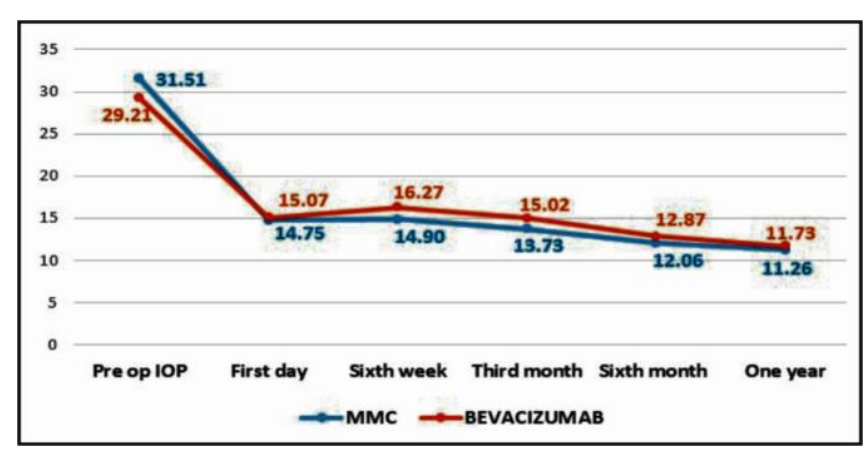

Figure I: Mean IOP Comparison between Mitomycin - $\mathrm{C}$ and Bevacizumab. ${ }^{*} \mathrm{IOP}=$ Intraocular pressure ${ }^{*} \mathrm{MMC}=$ Mitomycin $\mathrm{C}$ 
Table 4: Post-operative Mean Changes in BCVA (LogMar) between MMC and Bevacizumab.

\begin{tabular}{lccc}
\hline BCVA & MMC & Bevacizumab & P-value \\
\hline First day & $0.68 \pm 0.40$ & $0.63 \pm 0.41$ & 0.538 \\
Sixth week & $0.57 \pm 0.41$ & $0.42 \pm 0.35$ & 0.067 \\
Third month & $0.51 \pm 0.36$ & $0.36 \pm 0.29$ & 0.034 \\
Sixth month & $0.51 \pm 0.36$ & $0.35 \pm 0.23$ & 0.01 \\
One Year & $0.50 \pm 0.39$ & $0.38 \pm 0.27$ & 0.01 \\
\hline \multirow{3}{*}{ *IOP = Intraocular pressure } & *MMC = Mitomycin C \\
*BCVA = Best corrected visual acuity
\end{tabular}

\section{DISCUSSION}

The main cause of failure of trabeculectomy is excessive postoperative conjunctival scarring at the site of filtering bleb due to inflammatory reaction. To overcome this problem, several antimetabolites like 5 - fluorouracil and MMC had been used successfully with filtration surgery. Over last few years, anti-VEGF agents such as Bevacizumab has been introduced as a potent adjunct in trabeculectomy with good outcome in control of IOP. The fibroblasts of tenon capsule, which produce collagen and elastin are the most important mediators of ocular scar formation after filtration surgery. Various in vitro studies have shown effectiveness of anti-VEGF agent on corneal and conjunctival fibroblast. ${ }^{14-15}$

In this particular study, we compared IOP control after trabeculectomy with the adjunctive use of MMC and Bevacizumab. We report a significant reduction of IOP in both groups at one year $(p=0.001)$, with a reduction in IOP values of about $83 \%$ and $79 \%$ respectively. Both the groups were comparable in terms of IOP control at one year. In terms of bleb characteristics, we noticed increase in bleb vascularity in Bevacizumab group as compared to MMC group i.e., $34 \%$ and $19 \%$, at one year followup. Postoperative complication rates were slightly higher in MMC group, although statistically not significant. There was no difference in number of anti-glaucoma medications required at one year after surgery between the two groups.

Kahook et al. reported that Bevacizumab prevented excessive scar formation after needle bleb revision in failed trabeculectomy, a finding similar to our study. ${ }^{16}$ A study conducted by Sengupta et al. showed that sub-conjunctival Bevacizumab was equally effective in reducing IOP, with a better safety profile compared with MMC. The mean IOP was 16.2 $\pm 4.3 \mathrm{~mm} \mathrm{Hg}$ in their patients receiving $\mathrm{MMC}$ and $16.2 \pm 3.7 \mathrm{~mm} \mathrm{Hg}$ in Bevacizumab group at six months follow-up. ${ }^{13}$ Grewal et al. reported on the efficacy of a single postoperative injection of $1.25 \mathrm{mg} /$ $0.05 \mathrm{ml}$ of Bevacizumab in 12 glaucomatous eyes that underwent trabeculectomy. ${ }^{17}$ Their findings showed a reduction in mean IOP from $24.4 \mathrm{~mm} \mathrm{Hg}$ to 11.6 $\mathrm{mmHg}(52 \%)$ at six months' follow-up. In another study conducted by Jaya Kaushik and associates, adjunctive Bevacizumab in trabeculectomy was found to be effective and comparable to MMC for controlling IOP in POAG patients at one-year followup $(\mathrm{p}=0.43)$. However, there was statistically significant difference in peripheral bleb vascularity with Bevacizumab group exhibiting a low degree of vascularity at one year $(p=0.029) .{ }^{18}$ This finding is different from our study where we found increased bleb vascularity in Bevacizumab group at one year.

Akkan et al. showed the frequency of IOP control after one year in $41 \%$ and $46 \%$ of their patients receiving Bevacizumab and $\mathrm{MMC}$, respectively. ${ }^{11}$ Nilforushan et al, reported that $2.5 \mathrm{mg} / 0.1 \mathrm{ml}$ subconjuctival Bevacizumab application after primary trabeculectomy provided effective IOP control, but when compared to the MMC administered group, it was less effective. ${ }^{12}$ They observed a $56 \%$ fall of IOP in the MMC group, and $34 \%$ in the Bevacizumab group, after an average followup of 7 months. However, this study had a small sample size and short follow-up period that may be the reason for findings different from our study.

Xiaoyan Liu and associates found that Bevacizumab was an effective adjunct in trabeculectomy concerning the complete success rate, IOP and anti-glaucoma medications reduction when compared with placebo. However, its use increased the risk of bleb leakage and encysted bleb formation compared with MMC. ${ }^{19}$ This study had a shorter follow-up period of six months that may explain findings different from our study.

Kopsinis et al compared the effects of intracameral Bevacizumab to sub tenon Mitomycin $\mathrm{C}$ in trabeculectomy. They concluded that average IOP and glaucoma medications decreased significantly in both groups at all follow-up points compared to baseline $(p<0.001)$, without significant difference between groups at 3 years. ${ }^{20}$ Bilgic et al, compared the outcomes of trabeculectomy using two different routes of Bevacizumab administration as an adjunct in patients with primary open angle glaucoma. A significant reduction was observed in the IOP post trabeculectomy in all patients in both groups (paired t- 
test, $\mathrm{P}<0.001$, both groups), a change that had persisted at one-year follow-up. ${ }^{21}$ Another report found that Bevacizumab along with Mitomycin C in trabeculectomy was not superior to trabeculectomy with Mitomycin $\mathrm{C}$ or trabeculectomy with Mitomycin $\mathrm{C}$ and intracameral Bevacizumab. However, both groups showed a statistically significant reduction in IOP after 6 and 12 months $(\mathrm{p}-0.001) .^{22}$ Nadeem S, published her work of 30 patients who underwent trabeculectomy with adjunctive use of 5 - Fluorouracil $(5-\mathrm{FU})$ applied topically for 5 minutes. In half of the eyes, Bevacizumab was injected over scleral flap at the end of the procedure. After 3 months follow-up, IOP control and bleb appearance was indifferent between the two groups. The author concluded no added benefit of sub-conjunctival Bevacizumab. ${ }^{23}$

Limitations of our study are that 9 patients lost to follow-up in MMC group and 11 in Bevacizumab group at the end of one year. Secondly, followup was limited to one year. However, this study is a significant contribution to the available literature regarding glaucoma, particularly in Pakistan.

\section{CONCLUSION}

Adjunctive use of Mitomycin-C (MMC) or Bevacizumab with trabeculectomy are equally effective in reducing IOP in patients with diagnosis of primary open angle glaucoma. Though, vascularity of bleb was slightly increased in Bevacizumab group as compared to MMC group at one year followup, whereas postoperative complications were slightly lower in Bevacizumab group. These findings were statistically not significant.

\section{ACKNOWLEDGMENT}

This study is supported by a research grant from Ophthalmological society of Pakistan (OSP).

\section{Ethical Approval}

The study was approved by the Institutional review board/Ethical review board (A-00093).

\section{Conflict of Interest}

Authors declared no conflict of interest.

\section{REFERENCES}

1. Quigley HA, Broman AT. The number of people with glaucoma worldwide in 2010 and 2020. $\mathrm{Br} \mathrm{J}$ Ophthalmol. 2006; 90: 262-67.

2. Cairns JE. Trabeculectomy. Preliminary report of a new method. Am J Ophthalmol. 1968; 66: 673-8.

3. Skuta GL, Parrish RK. Wound healing in glaucoma filtering surgery. Surv Ophthalmol. 1987; 32: 149-70.

4. Addicks EM, Quigley HA, Green WR, Robin AL. Histologic characteristics of filtering blebs in glaucomatous eyes. Arch Ophthalmol. 1983; 101: 79598.

5. Greenfield DS, Suner IJ, Miller MP, Kangas TA, Palmberg PF, Flynn HW Jr. Endophthalmitis after filtering surgery with mitomycin. Arch Ophthalmol 1996; 114: 943-949.

6. Jurkowska-Dudzinska J, Kosior-Jarecka E, Zarnowski T. Comparison of the use of 5-fluorouracil and Bevacizumab in primary trabeculectomy: results at 1 year. Clin Experiment Ophthalmol. 2012; 40 (4): e135-42. Doi: 10.1111/j.1442-9071.2011.02608.x.

7. Hollo G. Wound healing and glaucoma surgery: modulating the scarring process with conventional antimetabolites and new molecules. Dev Ophthalmol. 2012; 50: 79-89.

8. Wilkins $\mathbf{M}$, Indar $\mathbf{A}$, Wormald. Intra-operative mitomycin $-\mathrm{c}$ in $\mathrm{C}$ for glaucoma surgery. Syst Rev. 2001; 2 (2): 28-97.

9. Chen CW, Huang HT, Bair JS, Lee CC. Trabeculectomy with simultaneous topical application of Mitomycin - $\mathrm{C}$ in refractory glaucoma. J Ocul Pharmacol. 1990; 6 (3): 175-182.

10. Cheng JW1, Cheng SW, Wei RL, Lu GC. Antivascular endothelial growth factor for control of wound healing in glaucoma surgery. Cochrane Database Syst Rev. 2016; 1: CD009782. Doi: 10.1002/14651858.CD009782.pub2.

11. Akkan JU, Cilsim S. Role of subconjunctival Bevacizumab as an adjuvant to primary trabeculectomy: a prospective randomized comparative 1-year follow-up study. J Glaucoma, 2015; 24 (1): 1-8.

12. Nilforushan $\mathbf{N}$, Yadgari $\mathbf{M}$, Kish $\mathbf{S K}$, Nassiri $\mathbf{N}$. Subconjunctival Bevacizumab versus mitomycin C adjunctive to trabeculectomy. Am J Ophthalmol. 2012; 153: 352-57.

13. Sengupta S, Venkatesh R, Ravindran RD. Safety and efficacy of using off-label Bevacizumab versus mitomycin $\mathrm{C}$ to prevent bleb failure in a single-site phacotrabeculectomy by a randomized controlled clinical trial. J Glaucoma, 2012; 21 (7): 450-9. Doi: 10.1097/IJG.0b013e31821826b2. 
14. Wilgus TA, Ferreira AM, Oberyszyn TM, Bergdall VK, Dipietro LA. Regulation of scar formation by vascular endothelial growth factor. Lab Invest. 2008; 88 (6): 579-90. Doi: 10.1038/labinvest 2008.36. Epub 2008 Apr 21. PMID: 18427552; PMCID: PMC2810253.

15. Li Z, Van Bergen T, Van de Veire S, Van de Vel I, Moreau H, Dewerchin M. et al. Inhibition of vascular endothelial growth factor reduces scar formation after glaucoma filtration surgery. Invest Ophthalmol Vis Sci. 2009; 50 (11): 5217-25.

16. Kahook MY, Schuman JS, Noecker RJ. Needle bleb revision of encapsulated bleb with Bevacizumab. Ophthalmic Surg Laser Imaging, 2006; 37: 148-50.

17. Grewal DS, Jain R, Kumar H, Grewal SP. Evaluation of subconjuctival Bevacizumab as an adjunct to trabeculectomy: a pilot study. Ophthalmology, 2008; 115 (12): 2141-2145. e2.

Doi: 10.1016/j.ophtha.2008.06.009. Epub 2008 Aug 9. PMID: 18692246.

18. Kaushik J, Parihar JK, Jain VK, Gupta S, Nath P, Durgapal P, et. al. Efficacy of Bevacizumab Compared to Mitomycin C Modulated Trabeculectomy in Primary Open Angle Glaucoma: A One-Year Prospective Randomized Controlled Study. Curr Eye Res. 2017; 42 (2): 217-224.

Doi: 10.3109/02713683.2016.1164188. Epub 2016 Jun 7. PMID: 27269279.

19. Liu X, Du L, Li N. The Effects of Bevacizumab in Augmenting Trabeculectomy for Glaucoma: A Systematic Review and Meta-Analysis of Randomized Controlled Trials. Medicine (Baltimore). 2016; 95 (15): e3223. doi: 10.1097/MD.0000000000003223. PMID: 27082560; PMCID: PMC4839804.

20. Kopsinis G, Tsoukanas D, Kopsini D, Filippopoulos T. Intracameral Bevacizumab Versus Sub-Tenon's Mitomycin C as Adjuncts to Trabeculectomy: 3-Year Results of a Prospective Randomized Study. J Clin Med. 2021; 10 (10): 2054. Doi: 10.3390/jcm10102054. PMID: 34064843; PMCID: PMC8151253.
21. Bilgic A, Sudhalkar A, Sudhalkar A, Trivedi M, Vasavada V, Vasavada S. et al. Bevacizumab as an Adjunct to Trabeculectomy in Primary Open-Angle Glaucoma: A Randomized Trial. J Ophthalmol. 2020; 2020: 8359398. Doi: 10.1155/2020/8359398. PMID: 32089872 ; PMCID: PMC7013315.

22. Rabina G, Barequet D, Mimouni M, Kurtz S, Shemesh G, Rosenblatt $A$, et al. Intracameral Bevacizumab role in trabeculectomy: A 1-year prospective randomized controlled study. Eur J Ophthalmol. 2020; 30 (6): 1356-1361.

Doi: 10.1177/1120672119874682. Epub 2019 Sep 9. PMID: 31496260.

23. Nadeem S. Subconjunctival Bevacizumab as an Adjunct to 5 - Fluorouracil Enhanced Trabeculectomy: Short Term Results. Pak J. Ophthalmol. 2018; 34 (4): 272-278.

\section{Authors Designation \& Contribution}

P. S. Mahar; Professor \& Dean: Concepts, Design, Manuscript preparation.

Sobia Tabassum; Senior Registrar: Data acquisition, Data analysis.

Mujahid Inam; Associate Professor: Manuscript review.

Muhammad Faaz Malik; Senior Registrar: Literature Search.

Tauseef Mahmood; Statistician: study Design. Statistical Analysis. 